\title{
Propofol use for sedation during endoscopy in adults: A Canadian Association of Gastroenterology position statement
}

\author{
Michael F Byrne MA MD (Cantab) MRCP FRCPC ${ }^{1}$, Naoki Chiba MD MSc FRCPC ${ }^{2}$, Harminder Singh MD MPH FRCPC ${ }^{3}$, \\ Daniel C Sadowski MD FRCPC ${ }^{4}$, for the Clinical Affairs Committee of the Canadian Association of Gastroenterology
}

\begin{abstract}
MF Byrne, N Chiba, H Singh, DC Sadowski; for the Clinical Affairs Committee of the Canadian Association of Gastroenterology. Propofol use for sedation during endoscopy in adults: A Canadian Association of Gastroenterology position statement. Can J Gastroenterol 2008;22(5):457-459.

Over the past decade, multiple clinical reports have demonstrated that the use of propofol sedation for gastrointestinal endoscopy by gastroenterologists and trained endoscopy nurses is safe and effective in appropriately selected patients. Proposed benefits of propofol sedation include rapid onset of action, improved patient comfort and rapid clearance, as well as prompt recovery and discharge from the endoscopy unit. As a result of medical evidence, a number of international professional societies have endorsed the use of propofol in gastrointestinal endoscopy. In Canada, no formal guidelines currently exist. In the present article, the Clinical Affairs Committee of the Canadian Association of Gastroenterology presents a position statement, incorporating updated information on the use of propofol sedation for endoscopy in adult patients.
\end{abstract}

Key Words: Conscious sedation; Endoscopy; Gastrointestinal endoscopy; General anesthesia; Propofol; Sedation

Dropofol is an intravenously administered, hypnotic drug initially developed for the induction and maintenance of general anesthesia. Over the past decade, multiple clinical reports in the scientific literature have demonstrated that the use of propofol for gastrointestinal endoscopy by gastroenterologists and trained endoscopy nurses is safe and effective in appropriately selected patients. Proposed benefits of propofol sedation include rapid onset of action, improved patient comfort and rapid clearance, as well as prompt recovery and discharge from the endoscopy unit.

As a result of medical evidence, three professional societies the American College of Gastroenterology, the American Gastroenterological Association and the American Society for Gastrointestinal Endoscopy - issued a joint statement in March 2004 (1), endorsing the use of propofol for endoscopy sedation by adequately trained endoscopists and endoscopy nurses. This position was reinforced in 2007 when the American Gastroenterological Association released a review of endoscopic sedation (2), which also addressed the medicolegal considerations associated with propofol use. In Canada, no formal guidelines currently exist, and the use of propofol for sedation in elective gastrointestinal endoscopy has been limited to a few interested practitioners. Given the inherent advantages

\section{Le recours à la sédation des adultes par le propofol pendant l'endoscopie : Un document de principes de l'Association canadienne de gastroentérologie}

\begin{abstract}
Depuis dix ans, de nombreux rapports cliniques ont démontré que le recours à la sédation par le propofol pour l'endoscopie intestinale effectuée par des gastroentérologues et des infirmières en endoscopie formées est sécuritaire et efficace chez des patients bien sélectionnés. Les bienfaits proposés de la sédation par le propofol sont la rapidité d'action, le plus grand confort des patients et la clairance rapide, de même que la récupération et le congé rapides de l'unité d'endoscopie. Étant donné les données médicales probantes, plusieurs sociétés professionnelles internationales approuvent le recours au propofol pour l'endoscopie gastro-intestinale. Au Canada, il n'existe pas de lignes directrices officielles à ce sujet. Dans le présent article, le comité des affaires cliniques de l'Association canadienne de gastroentérologie présente un document de principes qui contient de l'information à jour sur le recours à la sédation des adultes par le propofol pendant l'endoscopie.
\end{abstract}

${ }^{1}$ University of British Columbia, Vancouver, British Columbia; ${ }^{2}$ McMaster University, Hamilton, Ontario; ${ }^{3}$ University of Manitoba, Winnipeg, Manitoba; ${ }^{4}$ University of Alberta, Edmonton, Alberta

Correspondence: Dr Daniel C Sadowski, 331 Community Services Centre, Royal Alexandra Hospital, Edmonton, Alberta T5H 3 V9.

Telephone 780-735-6837, fax 780-735-5650, e-mail dan.sadowski@ualberta.ca

Received for publication February 27, 2008. Accepted March 2, 2008. 
- a quicker onset of action and less patient discomfort; both of which benefit the endoscopist and the patient (3-5); and

\section{- less nausea and vomiting (2,6-10).}

It should be recognized that adequate sedation can usually be achieved with a combination of opioids and benzodiazepines. As such, there is no mandate for endoscopists to switch to propofol, particularly because most operators have considerable experience administering standard agents.

There is some suggestion that the pharmacological profile of propofol may be particularly advantageous for prolonged and complex procedures in which patient cooperation is critical, such as endoscopic retrograde cholangiopancreatography and endoscopic ultrasound. However, less data exist on the safety of these procedures compared with standard gastroscopy and colonoscopy (11).

Potentially, the largest impact of propofol use will be related to faster recovery times and earlier discharges from the endoscopy unit. This increased throughput and efficiency may offset long waitlists.

Propofol is safe for use as a conscious sedation agent for endoscopy, when used by appropriately trained endoscopists and/or endoscopy nurses

The reported clinical experience for propofol sedation in endoscopy currently involves more than 200,000 patients. In these descriptions, propofol was administered by gastroenterologists $(7-9,12,13)$ and/or specially trained endoscopy nurses $(1,2,4,14-18)$. A recent meta-analysis (8) found no increase in the risk of cardiopulmonary complications with the use of propofol sedation for endoscopy, compared with the use of traditional sedative agents. There were no reports of patients requiring intubation or of sedation-related deaths. However, appropriate patient selection is critical, because a more recent study (11) reported a small number of deaths in patients with a high American Society of Anesthesiologists (ASA) class who received propofol during interventional procedures. Of note, none of the patients in this series underwent colonoscopy or elective gastroscopy. Thus, if the gastroenterologist administers the propofol, a nurse who cares only for the cardiorespiratory status of the patient should be present.

Despite the plethora of safety data relating to the use of propofol by endoscopists and endoscopy nurses, significant concerns remain within the medical community. It should be pointed out that similar concerns were raised when midazolam was first introduced for routine use in endoscopy. Because it is clear that patients who receive propofol can more easily slip into deep sedation, appropriate training and monitoring are required. Potential users of propofol are reminded that unlike benzodiazepines and opiates, there is no reversal agent for propofol.

Propofol should not be used in patients who are allergic to egg, soy or sulphites.

\section{Endoscopists are required to obtain training in the safe} administration of propofol before using it in clinical practice Currently, Canadian training programs in gastroenterology do not include 'monitored anesthesia care' for deep sedation. As well, there are neither firmly established criteria for appropriate training in propofol administration, nor standards for assessment of competence. The American Society for Gastrointestinal Endoscopy has published recommendations regarding the learning objectives required for formal training in propofol administration (19), and the Canadian Association of Gastroenterology endorses these guidelines. We strongly recommend that endoscopists seeking to use propofol in their practice should undergo:

1) certification in 'advanced cardiac life support'; and

2) a preceptorship or formal course of instruction with an individual (such as an anesthesiologist) who is familiar with propofol use.

The endoscopist and nursing staff should be competent in airway management, as per the advanced cardiac life support guidelines. However, we do not feel that it is mandatory that individuals be competent in endotracheal intubation, because severe respiratory depression should be extremely rare if this drug is used cautiously. Furthermore, it would be very difficult for such individuals to maintain their intubation skills, due to infrequent use (14). In addition, it may be advisable to have available staff on the premises that are able to intubate in an emergency situation.

\section{Appropriately trained endoscopy nurses can also administer} propofol for endoscopy

Nurse-administered propofol sedation for endoscopy has been examined in multiple clinical trials (1,2,4,14-18). Appropriate training for nurses is yet to be formalized, but a growing number of American centres are offering such training. Nurses administering propofol should ideally be involved solely in the monitoring of the patient and not in the endoscopy procedure. If the gastroenterologist administers the propofol, a nurse who cares only for the cardiorespiratory status of the patient should be present. Explicitly interpreted, two nurses (or one nurse and one endoscopy technician) would be required for cases involving propofol. In contrast to this recommendation, a recent study involving more than 27,000 patients found that a team of one physician endoscopist and one endoscopy nurse can safely administer propofol sedation for gastrointestinal endoscopy (18). However, in this situation, coadministration of a benzodiazepine, narcotic, or both, is usually needed to reduce the dose of propofol required. Any 'physician-nurse' team involved in propofol use should have the requisite training to deal with significant respiratory depression.

It is worth noting that several provinces are developing an 'anesthesia assistant' program, to train nurses and respiratory therapists to provide sedation for a range of procedures without the need for an anesthesiologist in the room (but present in the building). Such programs will undoubtedly help to safely establish propofol delivery by endoscopy nurses, and the change in staffing requirements highlights the cost-efficiency benefits associated with using this anesthetic.

\section{Patients receiving propofol for endoscopy should be diligently monitored}

The following parameters should be monitored for all patients receiving propofol: pulse oximetry, blood pressure, and electrocardiography and heart rate. Appropriate resuscitation equipment should be readily available for airway management. It is important to note that propofol may cause vasodilation and myocardial depression independent of hypoxia and hypoventilation. While technology exists for capnography, the current literature does not support such a routine, because no change in clinical outcomes has been documented (2). 
There are no formal dosing guidelines for propofol use in endoscopy. This agent should be given in incremental bolus loads or by continuous infusion, with extreme care taken to prevent inadvertent bolus doses

Other than the passage of time, there is no specific antidote for propofol. Caution is required during administration to avoid deep anesthesia. Generally, a propofol loading dose of $40 \mathrm{mg}$ to $50 \mathrm{mg}$ is given with further smaller bolus loads (10 mg to $20 \mathrm{mg}$ ) to maintain sedation, with a typical total dose between $100 \mathrm{mg}$ and $300 \mathrm{mg}$. Continuous infusions at $100 \mathrm{mg} / \mathrm{h}$ to $200 \mathrm{mg} / \mathrm{h}$ have also been used, but most investigators prefer the flexibility of the bolus approach $(20,21)$.

There is a growing body of evidence supporting the use of propofol in conjunction with small doses of benzodiazepines (eg, midazolam) and/or opiates (eg, fentanyl). With combination therapy, a smaller dose of propofol is required to obtain moderate rather than deep sedation $(12,22)$. In a recent study (22), patient recovery and discharge was faster with combination therapy than with propofol alone.

For low-risk endoscopy patients, routine involvement of anesthesiologists to administer propofol is not required Propofol was originally developed as a hypnotic agent for the induction of anesthesia and, as such, the product monograph

\section{REFERENCES}

1. Recommendations on the administration of sedation for the performance of endoscopic procedures. A joint statement of a working group from the American College of Gastroenterology (ACG), the American Gastroenterological Association (AGA) and the American Society for Gastrointestinal Endoscopy (ASGE). $<$ http://www.gastro.org/wmspage.cfm?parm1=371> (Version current at March 3, 2008).

2. Cohen LB, Delegge MH, Aisenberg J, et al, for the AGA Institute. AGA Institute review of endoscopic sedation. Gastroenterology 2007;133:675-701.

3. Ng JM, Kong CF, Nyam D. Patient-controlled sedation with propofol for colonoscopy. Gastrointest Endosc 2001;54:8-13.

4. Sipe BW, Rex DK, Latinovich D, et al. Propofol versus midazolam/meperidine for outpatient colonoscopy: Administration by nurses supervised by endoscopists. Gastrointest Endosc 2002;55:815-25. (Erratum in 2002;56:324).

5. Ulmer BJ, Hansen JJ, Overley CA, et al. Propofol versus midazolam/fentanyl for outpatient colonoscopy: Administration by nurses supervised by endoscopists. Clin Gastroenterol Hepatol 2003;1:425-32.

6. Jung M, Hofmann C, Kiesslich R, Brackertz A. Improved sedation in diagnostic and therapeutic ERCP: Propofol is an alternative to midazolam. Endoscopy 2000;32:233-8.

7. Koshy G, Nair S, Norkus EP, Hertan HI, Pitchumoni CS. Propofol versus midazolam and meperidine for conscious sedation in GI endoscopy. Am J Gastroenterol 2000;95:1476-9.

8. Qadeer MA, Vargo JJ, Khandwala F, Lopez R, Zuccaro G. Propofol versus traditional sedative agents for gastrointestinal endoscopy: A meta-analysis. Clin Gastroenterol Hepatol 2005;3:1049-56.

9. Vargo JJ, Zuccaro G Jr, Dumot JA, et al. Gastroenterologistadministered propofol versus meperidine and midazolam for advanced upper endoscopy: A prospective, randomized trial. Gastroenterology 2002;123:8-16.

10. Wehrmann T, Kokabpick S, Lembcke B, Caspary WF, Seifert H. Efficacy and safety of intravenous propofol sedation during routine ERCP: A prospective, controlled study. Gastrointest Endosc 1999;49:677-83.

11. Wehrmann T, Riphaus A. Sedation with propofol for interventional endoscopic procedures: A risk factor analysis. Scand J Gastroenterol 2007;Oct 10:1-7. (Epub ahead of print) presently states that "for general anesthesia or monitored anesthesia care or sedation, propofol injectable emulsion should be administered only by persons trained in the administration of general anesthesia and not involved in the conduct of the surgical/diagnostic procedure." However, propofol use has expanded outside of the operating room and has been used by nonanesthetists in other therapeutic areas such as the emergency department, for cardioversion, for intensive care unit sedation and in cardiac catheterization labs. While product labels alone do not establish standards of care, we would advocate a review of the product monograph so that amendments can reflect the changing use of propofol.

While there is no requirement for the routine involvement of anesthesiologists in the vast majority of endoscopic procedures, it should be noted that severe respiratory depression and sedation-related deaths have been reported when propofol has been used in high-risk interventional cases (11). Anesthesiology support should be considered for:

- individuals with difficult anatomy for ventilatory support (eg, obesity or thick necks);

- ASA class III or higher; and

- prolonged or high-risk interventional procedures.
12. Cohen LB, Hightower CD, Wood DA, Miller KM, Aisenberg J. Moderate level sedation during endoscopy: A prospective study using low-dose propofol, meperidine/fentanyl, and midazolam. Gastrointest Endosc 2004;59:795-803.

13. Yusoff IF, Raymond G, Sahai AV. Endoscopist administered propofol for upper-GI EUS is safe and effective: A prospective study in 500 patients. Gastrointest Endosc 2004;60:356-60.

14. Rex DK, Heuss LT, Walker JA, Qi R. Trained registered nurses/endoscopy teams can administer propofol safely for endoscopy. Gastroenterology 2005;129:1384-91.

15. Heuss LT, Schnieper P, Drewe J, Pflimlin E, Beglinger C. Risk stratification and safe administration of propofol by registered nurses supervised by the gastroenterologist: A prospective observational study of more than 2000 cases. Gastrointest Endosc 2003;57:664-71.

16. Rex DK, Overley C, Kinser K, et al. Safety of propofol administered by registered nurses with gastroenterologist supervision in 2000 endoscopic cases. Am J Gastroenterol 2002;97:1159-63.

17. Tohda G, Higashi S, Wakahara S, Morikawa M, Sakumoto H, Kane T. Propofol sedation during endoscopic procedures: Safe and effective administration by registered nurses supervised by endoscopists. Endoscopy 2006;38:360-7.

18. Kulling D, Orlandi M, Inauen W. Propofol sedation during endoscopic procedures: How much staff and monitoring are necessary? Gastrointest Endosc 2007;66:443-9.

19. Training committee. American Society for Gastrointestinal Endoscopy. Training guideline for use of propofol in gastrointestinal endoscopy. Gastrointest Endosc 2004;60:167-72.

20. Rex DK, Overley CA, Walker J. Registered nurse-administered propofol sedation for upper endoscopy and colonoscopy: Why? When? How? Rev Gastroenterol Disord 2003;3:70-80.

21. Chen SC, Rex DK. Review article: Registered nurse-administered propofol sedation for endoscopy. Aliment Pharmacol Ther 2004;19:147-55.

22. Van Natta ME, Rex DK. Propofol alone titrated to deep sedation versus propofol in combination with opioids and/or benzodiazepines and titrated to moderate sedation for colonoscopy. Am J Gastroenterol 2006;101:2209-17. 


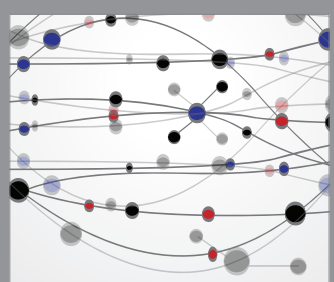

The Scientific World Journal
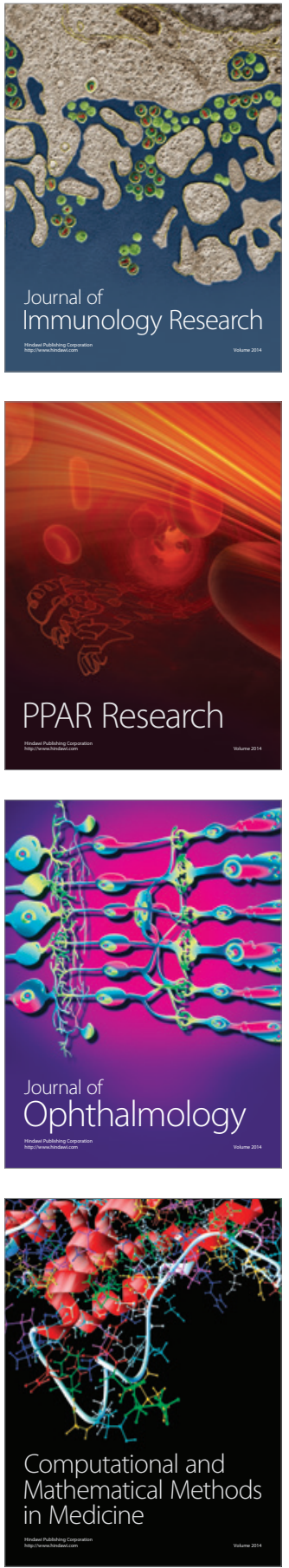

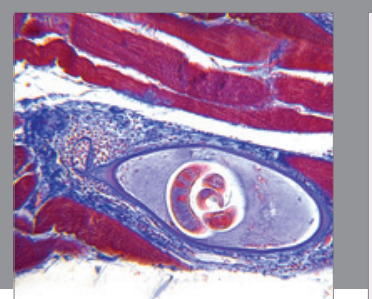

Gastroenterology Research and Practice

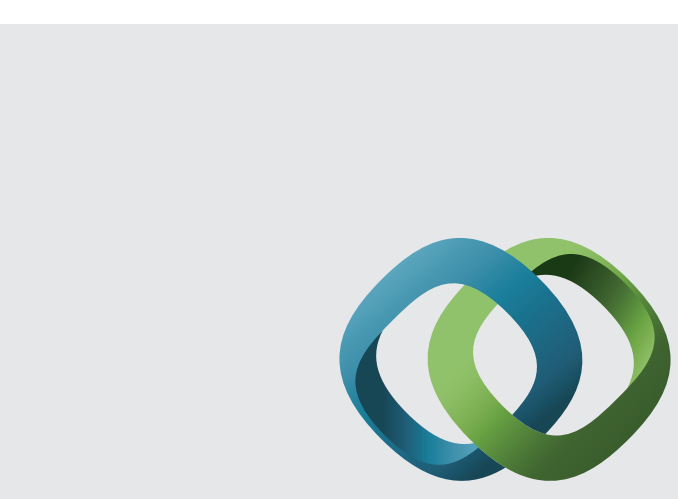

\section{Hindawi}

Submit your manuscripts at

http://www.hindawi.com
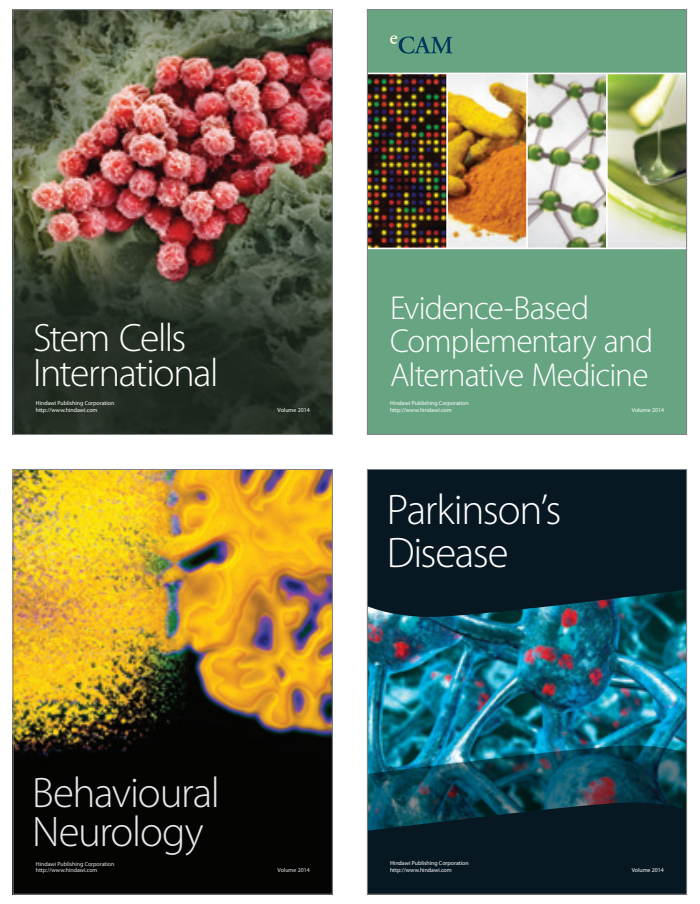
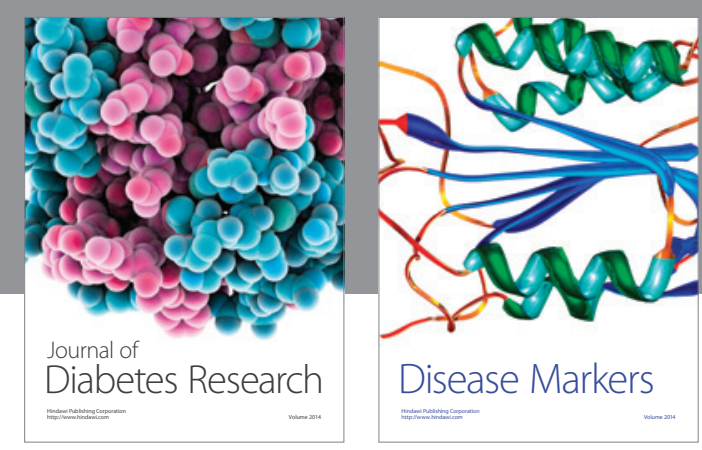

Disease Markers
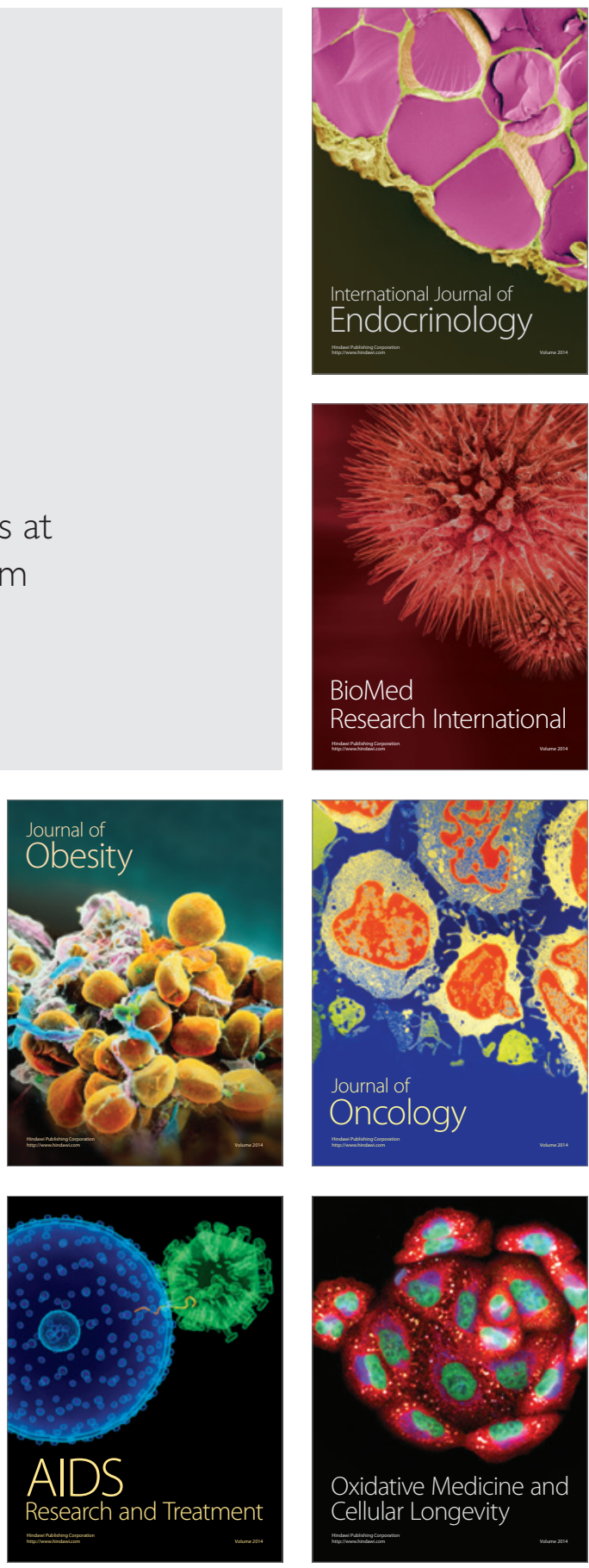